\title{
Hybrid appendectomy with classic trocar on McBurney's point
}

\author{
Mehmet Emin Gunes ${ }^{1}$, Feyzullah Ersoz ${ }^{2}$, Yigit Duzkoylu3 , Soykan Arikan², Coskun Cakir², Ali Emre Nayci \\ ${ }^{1}$ General Surgery Department, Bakirkoy Sadi Konuk Education and Research Hospital, Istanbul, Turkey \\ ${ }^{2}$ General Surgery Clinic, Istanbul Education and Research Hospital, Istanbul, Turkey \\ ${ }^{3}$ Gastroenterological Surgery Department, Turkiye Yuksek Ihtisas Education and Research Hospital, Ankara, Turkey
}

Videosurgery Miniinv 2018; 13 (1): 57-61

DOI: https://doi.org/10.5114/wiitm.2017.70323

\begin{abstract}
Introduction: Appendectomy is still the most commonly performed intra-abdominal operation worldwide. Interestingly, it has not reached the same popularity as other laparoscopic surgical procedures. Although multiple techniques have been described, a standard approach has not been described for the laparoscopic technique yet.

Aim: To perform hybrid appendectomy for acute appendicitis on McBurney's point, aiming to perform an easier and quicker procedure while limiting the trauma to the abdominal wall by obtaining the advantages of both laparoscopic and open techniques.

Material and methods: We retrospectively evaluated the results of 24 patients on whom we had performed hybrid appendectomy with an optical trocar on McBurney's point for acute appendicitis in 1 year in terms of demographics, operative time, complications, hospital stay and cosmetic results.

Results: Twenty-one of the patients underwent hybrid appendectomy with a one-optic trocar on McBurney's point. The mean operative time was $21.4 \pm 6.2 \mathrm{~min}$. We did not encounter any postoperative complications in any of the patients. The median hospital stay was $1.2 \pm 1.0$ days. The postoperative scar was minimal.

Conclusions: This technique is defined in the literature for the first time, and it is easy and feasible for the surgeons. It may reduce the operative time and costs when compared to the conventional laparoscopic technique, but prospective studies with more patients are needed for more certain results.
\end{abstract}

Key words: laparoscopic surgery, appendectomy, hybrid, conventional.

\section{Introduction}

Acute appendicitis is the most common etiology of acute abdomen and appendectomy is still the most commonly performed intra-abdominal operation worldwide. Open appendectomy (OA) is a simple, safe, quick, and effective procedure. Although de Kok introduced the laparoscopic method for the first time in 1977 [1], it has not reached the same popularity as other laparoscopic surgical procedures. However, randomized controlled studies have demonstrated the safety and efficiency of laparoscopic appendecto- my compared with open appendectomy for the treatment of acute appendicitis [2, 3]. Although multiple techniques have been described by various surgeons for laparoscopic appendectomy (LA) with respect to port establishment and removal of the appendix, a standard approach has not been described for the laparoscopic technique yet [4-8].

\section{Aim}

We performed a hybrid appendectomy for acute appendicitis on McBurney's point. Our aim was to

\section{Address for correspondence}

Assoc. Prof. Feyzullah Ersoz, General Surgery Clinic, Istanbul Education and Research Hospital, Samatya, Fatih 34000 Istanbul, Turkey, phone: +90 2124590000, e-mail: feyzullahersoz@gmail.com 


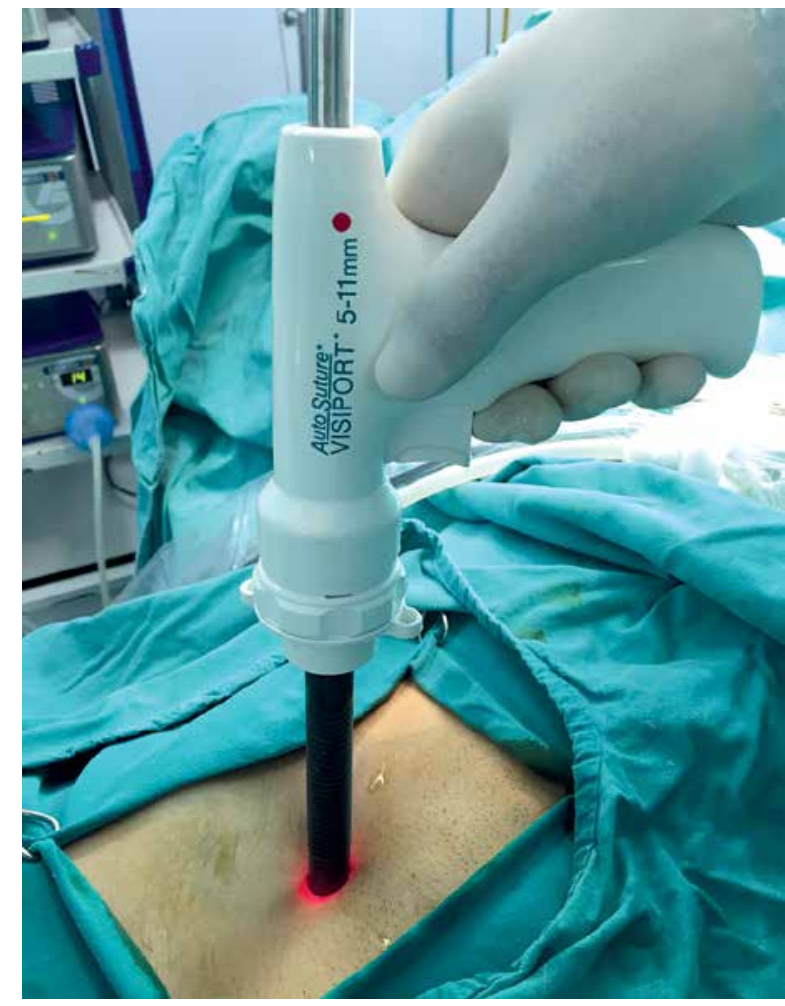

Photo 1. Introduction of the $11 \mathrm{~mm}$ optical trocar with $0^{\circ}$ telescope into the abdomen

perform an easier and quicker procedure while limiting the trauma to the abdominal wall by obtaining the advantages of both LA and OA techniques.

\section{Material and methods}

Following the approval of the ethics committee, we retrospectively evaluated the results of 24 patients (15 males, 9 females) on whom we had performed hybrid appendectomy with a one-optical

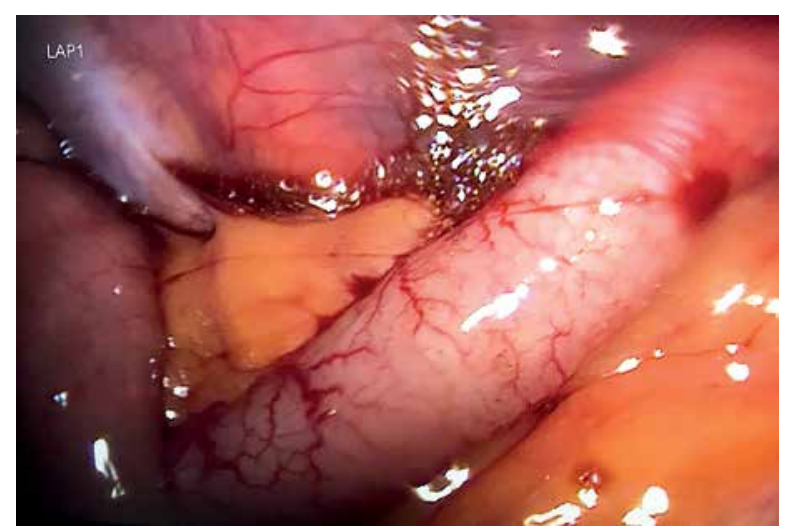

Photo 2. Visualization of the appendix or classic trocar on McBurney's point for acute appendicitis between January and December 2015 in terms of demographics, operative time, complications, hospital stay and cosmetic results.

\section{Operative technique}

In this technique, patients are placed in the supine position. They receive therapeutic antibiotics intravenously at the induction of general anesthesia. A Foley catheter is inserted to decompress the bladder. The operator and assistant stand on the left side of the patient while the monitor is placed on the right side. The patient is kept in the Trendelenburg position with his/her left side downwards. Following a 12-mm oblique incision on McBurney's point, an $11 \mathrm{~mm}$ optical trocar with $0^{\circ}$ telescope is introduced to the abdomen (Photo 1 ). Unless an optical trocar is used, a $12-\mathrm{mm}$ oblique incision is made on the same point and, after reaching the intra-abdominal cavity, a classic $10-\mathrm{mm}$ trocar is introduced. Pneumoperitoneum is initiated with a pressure of $14 \mathrm{~mm} \mathrm{Hg}$. Following the visualization of the appendix (Photo 2) and being sure there are not any other macroscopic intra-abdominal pathologies, the trocar is extracted and the abdominal wall is expanded together with the skin with the help of two retractors. The aim is to provide the insertion of the trocar together with the laparoscopic clinch back to the abdominal cavity. Then, the abdomen is insufflated again, and the appendix is held with the clinch (Photo 3) and extracted out with the trocar (Photo 4). Following this procedure, the conventional OA technique is performed (Photo 5). The appendiceal stump is sent back to the cavity (Photo 6) and the fascia is closed with 2-0 vicryl. The skin is

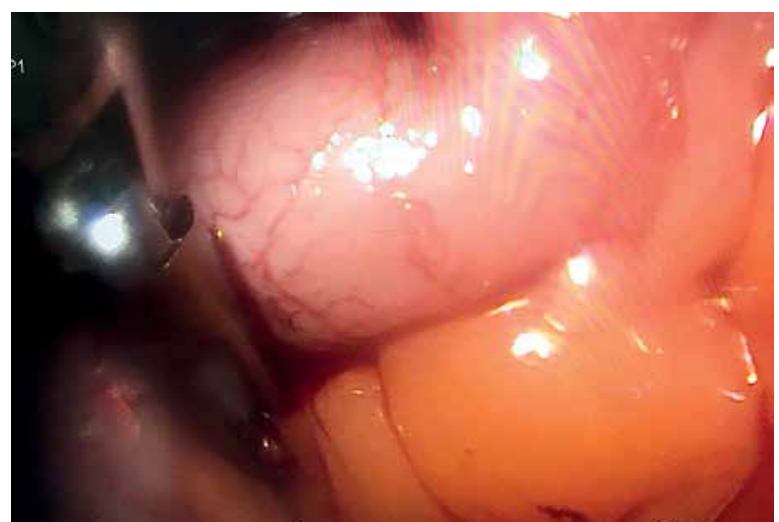

Photo 3. Holding the appendix with the clinch 


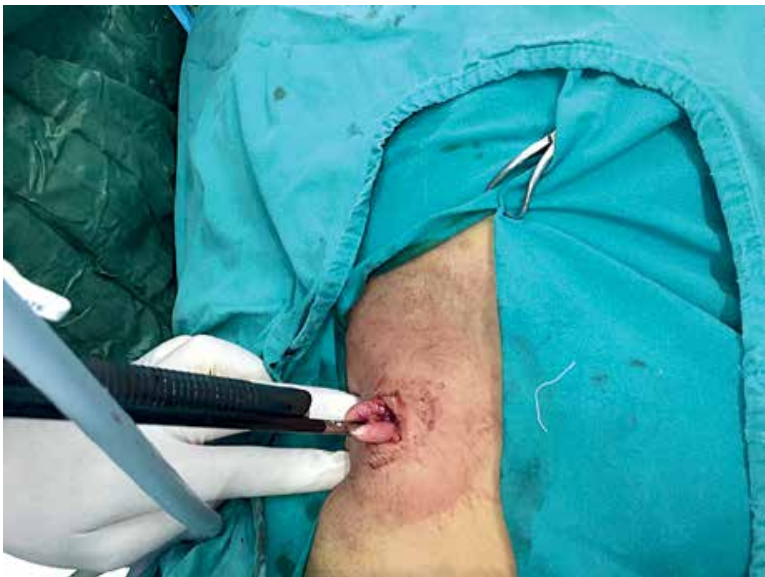

Photo 4. Extraction of the appendix with the trocar

closed subcutaneously or with interrupted sutures using absorbable material.

\section{Results}

This study included 15 males and 9 females who had undergone operations for uncomplicated acute appendicitis with a mean age of $26.8 \pm 5.2$ years. The mean body mass index (BMI) was $23 \pm 4.9 \mathrm{~kg} / \mathrm{m}^{2}$. Twenty-one of the patients were operated on with the technique of hybrid appendectomy with a one-optic trocar on McBurney's point. The appendix could not be visualized in 3 of the patients. In 2 of those 3 patients, a conventional laparoscopic technique was performed with an extra 10-mm trocar from the umbilicus and a 5-mm trocar from the suprapubic region. In 1 patient, the operation was converted to a conventional open technique.

The mean operative time was $21.4 \pm 6.2 \mathrm{~min}$ in 21 patients. Postoperatively oral liquids were started within $6 \mathrm{~h}$, solid food on the next day. Pathologic examination revealed acute appendicitis in all of the cases. We did not encounter any postoperative complications in any of the patients. The median hospital stay was $1.2 \pm 1.0$ days. The postoperative scar was minimal.

\section{Discussion}

Although numerous randomized controlled studies have demonstrated the safety and efficiency of laparoscopic appendectomy when compared with open appendectomy for the treatment of acute appendicitis [2, 3], LA is still far from being a gold

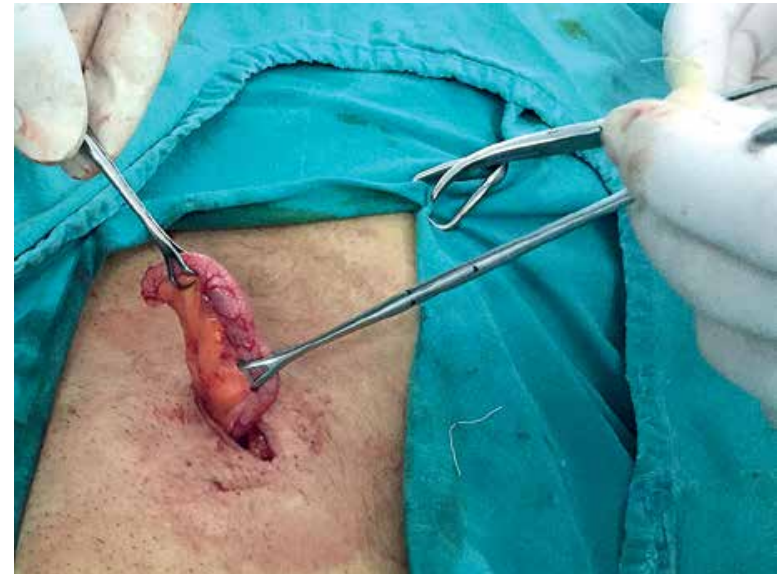

Photo 5. Conventional open appendectomy

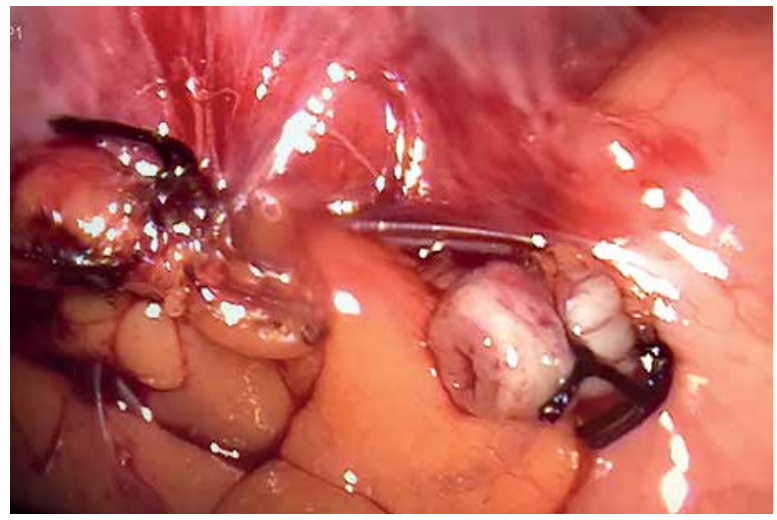

Photo 6. Appendiceal stump is sent back to the cavity

standard technique [9-11], conversely to cholecystectomy, adrenalectomy or gastro-esophageal reflux procedures. The underlying reasons are the convenience of the open technique and easy accessibility of the appendix with OA, with a short operative time. Many surgeons still do not find LA necessary when compared to OA.

Most of the studies have shown that LA lasts longer, but it is associated with a shorter hospital stay and possibly with a more rapid return to work [12]. Reduced incidence of wound infection and postoperative intestinal obstruction rates are also among the major advantages of laparoscopy [13].

Various techniques have been defined for shortening operative time and reducing scar formation such as transumbilical laparoscopic assisted single port appendectomy (TULA) technique and transumbilical laparoscopic single port appendectomy [1417] or using the help of a needle grasper [18]. In pe- 
diatric patients, TULA with extracorporeal ligation of the mesoappendix has been shown to reduce time needed for port access and closure when compared to conventional OA. This technique is easy in pediatric patients, in whom McBurney's point is close to the umbilicus. However, in elderly patients it is harder to access the appendix from umbilical region, which may lengthen operative time.

In a study that compared conventional multiport laparoscopic appendectomy (CMLA) with single site multiport umbilical laparoscopic appendectomy (SMULA), mean operative times were found to be nearly equal in both groups (43 min). However, cosmetic results were reported to be better in the SMULA group [19].

In our technique, we do not need single port or other instruments that require larger skin incisions. In our cases, we used the same trocar as we performed in standard laparoscopic procedures and the trocar was sent into the abdominal cavity through McBurney's point, which is the standard incision region in conventional OA. We believe that this technique reduces the operative time and costs by requiring fewer ports and not using any energy devices. Conversely, LA has been shown to extend operative time when compared to OA. In previous studies, LA has been shown to reduce overall costs, although many surgeons still think otherwise [20].

The most important advantage of LA is the wide exploration of the abdominal cavity. In OA, surgeons usually do not have the chance to examine all sites of the abdominal cavity, especially if the patient is obese or the diagnosis has some doubts. In our technique, we can observe all sites of the abdominal cavity without the need for more trocars and are able to visualize the appendix very easily in most cases. The fact that the appendix may not be easily observable despite a large skin incision extends the advantage of our technique.

We succeeded in 21 out of 24 patients, with the mean operative time of $21 \mathrm{~min}$, which is reasonably shorter than LA, even shorter than OA procedures. Additionally, we provided the advantage of minimal incision, pain and scar formation when compared to both LA and OA.

\section{Conclusions}

This technique is defined in the literature for the first time, and it is easy and feasible for surgeons.
It may reduce the operative time and costs when compared to LA, but prospective studies with more patients are needed for more certain results.

\section{Conflict of interest}

The authors declare no conflict of interest.

\section{References}

1. de Kok HJ. A new technique for resecting the non-inflamed not-adhesive appendix through a mini-laparotomy with the aid of the laparoscope. Arch Chir Neerl 1977; 29: 195-8.

2. Sauerland S, Lefering R, Holthausen U, Neugebauer EAM. Laparoscopic vs conventional appendectomy: meta-analysis of randomized controlled trials. Langenbeck's Arch Surg 1998; 383: 289-95.

3. Sauerland S, Lefering R, Neugebauer EA. Laparoscopic versus open surgery for suspected appendicitis. Cochrane Database Syst Rev 2004; 4: CD001546.

4. Ng WT, Sze SY, Hui SK. Port placement for laparoscopic appendectomy with the best cosmesis and ergonomics. Surg Endosc 2003; 17: 166-7.

5. D'Souza FR, Anwar MA, Audisio RA, Memon MA. A simple and inexpensive method for laparoscopic appendectomy. Surg Technol Int 2007; 16: 93-6.

6. Saad M. Fisherman's technique, introducing a novel method for using the umbilical port for removal of appendix during laparoscopic appendectomy. Surg Laparosc Endosc Percutan Tech 2007; 17: 422-4

7. Singh MK, Kumar MK, Mohan L. Suprapubic approach for laparoscopic appendectomy. J Nat Sci Biol Med 2013; 4: 389-92.

8. Zhang Z, Wang Y, Liu R, et al. Suprapubic single-incision versus conventional laparoscopic appendectomy. J Surg Res 2016; 200: 131-8.

9. Soper NJ, Stockmann PT, Dunnegan DL, Ashley SW. Laparoscopic cholecystectomy. The new 'gold standard'? Arch Surg 1992; 127: 917-21.

10. Frazzoni M, Piccoli M, Conigliaro R, et al. Laparoscopic fundoplication for gastroesophageal reflux disease. World J Gastroenterol 2014; 20: 14272-9.

11. Vereczkei A, Molnár A, Horváth OP. Minimally invasive technique as the gold standard of adrenal surgery. Magy Seb 2012; 65: 365-9.

12. Eypasch E, Sauerland S, Lofering R, Neugebauer EAM. Laparoscopic versus open appendectomy: between evidence and common sense. Dig Surg 2002; 19: 518-22.

13. Guller U, Hervey S, Purves $\mathrm{H}$, et al. Laparoscopic versus open appendectomy: outcomes comparison based on a large administrative database. Ann Surg 2004; 239: 43-52.

14. Esposito C. One-trocar appendectomy in pediatric surgery. Surg Endosc 1998; 12: 177-8.

15. Vidal O, Valentini M, Ginestà C, et al. Laparoendoscopic single-site surgery appendectomy. Surg Endosc 2010; 24: 686-91.

16. van der Linden YT, Boersma D, van Poll D, et al. Single-port laparoscopic appendectomy in children: single center experience in 50 patients. Acta Chir Belg 2015; 115: 118-22. 
17. Xue C, Lin B, Huang Z, Chen Z. Single-incision laparoscopic appendectomy versus conventional 3-port laparoscopic appendectomy for appendicitis: an updated meta-analysis of randomized controlled trials. Surg Today 2015; 45: 1179-86.

18. Donmez T, Sunamak O, Ferahman S, et al. Two-port laparoscopic appendectomy with the help of a needle grasper: better cosmetic results and fewer trocars than conventional laparoscopic appendectomy. Videosurgery Miniinv 2016; 11: 105-10.

19. Jategaonkar PA, Yadav SP. Single site multiport umbilical laparoscopic appendicectomy versus conventional multiport laparoscopic appendicectomy in acute settings. Ann R Coll Surg Engl 2014; 96: 452-7.

20. Smigielski JA, Piskorz L, Koptas W. Comparison of treatment costs of laparoscopic and open surgery. Videosurgery Miniinv 2015; 10: 437-41.

Received: 25.05.2017, accepted: 2.09.2017. 